\title{
Identidad etnosociolingüística y política lingüística. A propósito del Paraguay contemporáneo
}

\author{
Ethno-sociolinguistic identity and language policy. \\ The case of contemporary Paraguay
}

\author{
HENRI BOYER \\ Université Paul-Valéry Montpellier 3 / \\ Laboratoire DIPRALANG \\ henri.boyer@univ-montp3.fr \\ ORCID iD: 0000-0002-I925-6I32
}

Recibíu / Received: Io-IX-20 I 8

Aceptáu / Accepted: I4-I-20I9

RESUMEN. En esta contribución me propongo analizar el papel de las representaciones etnosociolingüísticas en la dinámica actual de una configuración bi/plurilingüe, la del Paraguay, "pluricultural y bilingüe", en la que la lengua mayoritaria (el guaraní) está en situación de minor(iz)ación y donde se está desarrollando una acción glotopolítica oficial con el objetivo de permitir que la lengua minorizada recupere o conquiste las funciones sociales normales de una lengua histórica, como es el caso del castellano en el mismo país. Es obvio que si bien la importancia de las circunstancias demolingüísticas no se puede negar, lo que sí se tiene que valorar es la importancia de los imaginarios sociolingǘsticos en la evolución positiva o negativa del conflicto que atraviesa toda la comunidad lingüística, según el tipo de política lingüística institucional que se ha (o no se ha) implementado. Se trata al fin y al cabo del éxito o del fracaso de la normalización lingüística y del impacto en el proceso glotopolítico de la lealtad lingüística, actitud ligada a representaciones etnosociolingüísticas identitarias.

Palabras clave: representación etnosociolingüística, identidad, nacionalismo lingüístico, guaraní, castellano.

ABSTRACT. The aim of this contribution is to analyze the role of ethno-sociolinguistic representations in the current dynamics of a bi/multi-lingual setting, the "multicultural and bilingual" Paraguay, where the majority language of the country (Guarani) is in a minorization process, and where an official glotto-political action is being taken with the aim to allow the minority language to recover or conquer the social functions of a historical language, as is the case of Castilian (Spanish) in the same country. Although the importance of demo-linguistic circumstances cannot be denied, it is obvious that the relevance of the sociolinguistic imaginary in the positive or negative evolution of the conflict and its relation with the type of institutional language policy that has (or has not) been implemented needs to be stressed . It is, after all, the success or failure of linguistic normalization and the impact on the glotto-political process of linguistic loyalty which is at issue, an attitude which is itself linked to ethno-linguistic identity representations.

Keywords: ethno-sociolinguistic representation, identity, linguistic nationalism, Guarani, Castilian. 
Cómo CITAR / Form of CITATION: Boyer, Henri (2019): "Identidad etnosociolingüística y política lingüística. A propósito del Paraguay contemporáneo", Glosema, I, pp. 4I-5 I. https://doi.org/Io.I78I I/glosema.I.20I9.4I-5I.

\section{INTRODUCCIÓN}

Cundo se analiza la situación sociolingüística (compleja) de Paraguay, en plena reorganización institucional, se puede apreciar la importancia de las representaciones identitarias (y el impacto del nacionalismo lingüístico) (Boyer y Penner 20I2). El guaraní, lengua indígena, es en Paraguay el epicentro de un interdiscurso dominante que celebra a la nación paraguaya, una nación mestiza, que se enorgullece de haber elevado al rango de idioma oficial una lengua precolombina ${ }^{1}$.

Es innegable, sin embargo, que también hay una percepción bilingüista en relación con un elogio nacionalista del mestizaje (el sociolingüista B. Melià habla de un "bilingüismo nacionalista”): la cuestión de la(s) identidad(es) y su gestión institucional es un tema clave de la sociedad paraguaya, que presenta diversas formas de heterogeneidad cultural y etnolingüística (entre I7 y 20 lenguas indígenas o dialectos hablados en comunidades indígenas, un bilingüismo social guaraní-castellano y varias lenguas extranjeras habladas por comunidades de asentamientos más o menos recientes) (Melià I997 [I988]; cf. también Zajícová 2009)

En I967, una nueva Constitución hizo del guaraní el idioma nacional de Paraguay, pero el castellano siguió siendo el único idioma oficial. No fue hasta I992, durante la redacción de una Constitución democrática, cuando se adoptó la cooficialidad del guaraní y del castellano. En 20 Io, ambas cámaras del Parlamento votaron la Ley N. ${ }^{0} 425$ I de Lenguas para establecer una política lingüística que pudiera promover efectivamente el carácter "pluricultural y bilingüe” de la sociedad paraguaya (proclamado por la Constitución, art. I40).

\section{La CONFiguración etnolingüística del Paraguay}

Como es sabido, el Paraguay — donde se habla mayoritariamente el guaraní (paraguayo), lengua descendiente de la familia amerindia tupí-guaraní, que se ha podido considerar dominante y dominado (Melià I 997 [I988]) - , presenta una configuración etnosociolingüística (de tipo diglósico o más bien pluriglósico) particularmente interesante. Hoy en día, esta configuración está en plena evolución con la aplicación de una reforma educativa que tiene como objetivo promover la educación bilingüe en todo el país. A pesar de que todos los indicadores institucionales auguran una

\footnotetext{
${ }^{1}$ A pesar de que la auténtica lengua vernácula de los paraguayos es una variante muy mestizada del guaraní, el jopara/yopará, que ha sido ampliamente estudiada ( $c f$., por ejemplo, Penner 2010).
} 
ruptura con un largo período de minoración (en el que el guaraní estuvo alternativamente excluido de la escuela, estigmatizado con la designación de guarango y mitificado, objeto de fetichismo), uno se pregunta si la representación ambivalente hacia el idioma de los orígenes — símbolo casi unánime de la identidad nacional a pesar de ser despreciado y minorizado (Manrique Castañeda, apud Melià I997 [I988]: 47) - pertenece ya al pasado. De hecho, diversas observaciones llevan a pensar que la actitud paradójica sufrida por la lengua guaraní, como lengua dominada, no ha desaparecido realmente.

A pesar de todo, en casi el $60 \%$ de los hogares el guaraní es la lengua habitual, porcentaje más alto que el de los hogares donde el castellano es habitual (35\%) (cf. Corvalán 2006: I 5-16). Esto muestra hasta qué punto esta configuración etnosociolingüística, en lo que se refiere a los repertorios y a los usos, es atípica dentro del conjunto de la hispanofonía de América Latina, donde la lengua del colonizador, el español, es típicamente dominante, si no exclusiva.

$\mathrm{Al}$ mismo tiempo, otra encuesta pone de manifiesto la permanencia de representaciones ambivalentes: mientras que el $77.6 \%$ de los encuestados están en desacuerdo con la afirmación de que "en el Paraguay está bien saber hablar sólo en guaranî" y mientras que sólo el 33.4 \% aprueban la afirmación de que "para progresar económicamente, uno tiene que saber hablar guaraní", el 8I.3\% considera que "la lengua guaraní está en [su] sangre”, resultado que confirma que el 71.3\% de los encuestados esté de acuerdo con la declaración de que "para ser auténticamente paraguayo, uno tiene que saber hablar guaraní” (Gynan 2003: 76-80).

G. Corvalán (I98 I [I977]: 4I) observa el "alto grado de nacionalismo que nace del uso del guaraní”. Pero tampoco se puede negar la existencia de otra percepción endógena en relación con el elogio nacionalista del mestizaje. Según Zajícová (2009: 58), "el orgullo se relaciona con el bilingüismo, y no con el guaraní solo". O sea que la cuestión de la(s) identidad(es) y su gestión oficial es clave en la sociedad paraguaya, habitada por varias modalidades de heterogeneidad cultural y etnosociolingüística.

\section{El COMPONENTE IDENTITARIO, ¿¿UN EJE IDEOlógico FUndamental?}

Es obvio que la 'identidad' es una noción polémica, sin embargo muy presente en el discurso mayoritario de las ciencias humanas y sociales. J.-L. Amselle (200I: I35), por ejemplo, denuncia una "propensión creciente al endurecimiento de las identidades”, observación compartida (sin denuncia) por J. A. Fishman (200I: 257), 
para quien "el último tercio del siglo XX quedó marcado por un renacimiento étnico" ${ }^{2}$.

Sin embargo, y paradójicamente, la diabolización de lo identitario puede acompañar tanto a la celebración de la unidad fundamental - y fundacional- (cuando el centro pretende excluir identidades periféricas), como a la heterogeneidad y el "mestizaje" (cuando tratan de combatirse posiciones antiinmigración, por ejemplo). El posicionamiento que yo defiendo considera que no es pertinente oponer (por lo menos en lo que toca a los funcionamientos del lenguaje en particular) identidad y heterogeneidad, identidades y unidad. La actividad cultural y, por lo tanto, etnosociolingüística de los grupos y comunidades se despliega, a mi parecer, en el marco de una dinámica de dos polos: uno orientado hacia una regulación/gestión centrípeta; otro, hacia la construcción centrífuga de identidades y/o de las manifestaciones de heterogeneidad. Reconocer la normalidad de esta tensión no significa desconocer el principio básico según el cual "la identidad no es algo dado y tampoco una esencia", sino que, al contrario, "es el resultado de una producción significante que la sociedad [en materia de lenguaje, en particular] permite, ordena, controla" (Lafont I $986: 8)^{3}$.

La sociedad paraguaya actual es un terreno de observación privilegiado para los que se interesan por la producción de identidad cultural y lingüística (nacional, fundamentalmente). Presenta una configuración etnosociolingüística compleja en la que la tensión identidad-homogeneidad/identidades-heterogeneidad se observa simultáneamente a través de manifestaciones aparentemente paradójicas que justamente demuestran el carácter dinámico de esta tensión.

Primero, hay que destacar la existencia de una modalidad lingüística de la que se ha debatido mucho: el jopara, variante interlectal del guarani paraguayo, en ocasiones meramente identificado con este guaraní mestizado en el curso de los siglos. Los especialistas (docentes y/o investigadores) favorables al guaraní normativo, enseñado, tienen dificultad para defender la legitimidad del guaraní escolar, en contra de la actitud de la mayoría de los usuarios, que consideran el guaraní hablado (el jopara) como la verdadera lengua del pueblo paraguayo. Y, por otra parte, es cierto que el guaraní popular no lo reivindican los indios que hablan un guaraní étnico, el cual quieren conservar en su integridad, particularmente oponiéndose a una escolarización en guaraní (enseñado) que puede poner en peligro una identidad singular preservada del mestizaje que han consentido (¿o que han sufrido?) la mayoría de los

\footnotetext{
${ }^{2}$ Nota del editor: ambas citas se ofrecen en la traducción al español del propio H. Boyer.

${ }^{3}$ Nota del editor: el texto de Lafont se presenta ya traducido al español por el propio H. Boyer.
} 
descendientes de los indios colonizados. O sea que la producción y el control de identidad(es) es un hecho básico en Paraguay. El asunto de la identidad nacional del Paraguay y de su dimensión etnosociolingüística — fundamental— se ha planteado con fuerza a propósito de la elaboración de una nueva constitución en dos momentos de la segunda mitad del siglo XX.

En 1967, en plena era Stroessner, a pesar de las recomendaciones del II Congreso Internacional de la Lengua y Cultura Guaraní-Tupí, la Convención Nacional Constituyente consideró el guaraní simplemente como una de las dos lenguas nacionales, siendo el español la única lengua oficial. A pesar de las intervenciones de varios constituyentes que elogiaron el guaraní:

[...] no le quitemos a nuestra Patria lo que, si se le busca una esencia, una esencia que constituya la fuerza de permanencia del paraguayo, es el idioma guaraní. (F. Levi Ruffinelli, Diario de Sesiones, CNC 1967, p. 46; apud Zuccolillo F. 2000: 173)

Cómo hemos de desconocer, Ciudadano Presidente, toda la dulzura de nuestra lengua nativa, toda esa honda expresión de los vocablos en guaraní, esa lengua que [...] nos hace sentirnos hermanos como paraguayos, porque cuando el paraguayo habla en guaraní con el paraguayo, olvida todas sus malquerencias, sus diferencias y sólo se siente paraguayo. (H. G. Lebrón, Diario de Sesiones, CNC 1967, p. 60; apud Zuccolillo F. 2000: 150 )

la postura favorable a seguir con la hegemonía institucional del castellano consiguió ser mayoritaria:

Vayamos al problema de la comunicación internacional y aceptemos las limitaciones que tiene este idioma [el guaraní], que por ser precisamente genuino nuestro, no tiene la universalidad como para conocer culturas, expresiones de arte y otras manifestaciones del pensamiento. (F. Levi Ruffinelli, Diario de Sesiones, CNC i967, p. 46; apud Zuccolillo F. 2000: I 59]) $)^{4}$

Se ha contemplado justamente el derecho y el deber que tiene el pueblo paraguayo de hablar el idioma guaraní, pero se han previsto, como dije, situaciones especiales que se refieren ya no a lo que está hablando el pueblo, no ya a lo que toca al alma popular o a la sensibilidad de nuestra Patria, sino sencillamente a hechos en los cuales existen otros problemas que, como repito, son las relaciones internacionales, los documentos oficiales y los instrumentos públicos ${ }^{5}$. (González Alsina, Diario de Sesiones, CNC 1967, p. 50 [apud Zuccolillo F. 2000: I 83])

\footnotetext{
${ }^{4}$ Es el mismo constituyente que había alabado el idioma guaraní recurriendo al mito de la fusión que generó el mestizaje paraguayo (Zuccolillo F. 2000: I74): “[...] voy a pedir disculpas por abogar en castellano por el guaraní, quizás sea el tributo del español a la india que vino a formar esta raza maravillosa nuestra” (F. Levi Ruffinelli, Diario de Sesiones, CNC i967, p. 45).

${ }^{5}$ Es la demostración perfecta de cómo se neutralizan a favor de lo negativo los componentes estereotípicos de la representación ambivalente de una lengua dominada en una situación de conflicto diglósico, apoyando así la dominación a favor de la lengua dominante (Boyer 2007).
} 
En 1992, después del retorno de la democracia, se trataba de hacer lo que no habían querido/podido los constituyentes de 1967: dar al guaraní el estatuto de lengua cooficial, en particular por una mera consideración demolingüística (siendo el guaraní la lengua mayoritaria del país), sin olvidar una exigencia de lealtad por la lengua de las raíces muy vigente. Lo que no implica, por supuesto, que hayan desaparecido las "imágenes lingüísticas dicotómicas” (Zuccolillo F. 2000: I 52). Pero se puede pensar que la Constitución de 1992 significaba una ruptura entre una época de ideología diglósica dominante y el advenimiento de un nacionalismo lingüístico cuyo epicentro era el guaraní.

Así lo indican los discursos de los participantes a un grupo de discusión formado por estudiantes de la Universidad Católica de Asunción en 2007 (aunque la realidad del imaginario colectivo necesita una observación más profunda ${ }^{6}$. Queda claro el consenso en lo que respecta al estatuto actualizado del guaraní, incluso entre los noguaranófonos, como lo indica el primer extracto:

[...] CA: ¿̨cómo/ cómo os identificáis con relación a / otros pueblos sudamericanos?

[...] Gi: en mi caso el guaraní por ejemplo es // una parte que identifica al Paraguay pero yo no me puedo sentir identificado porque yo no sé hablar guaraní / una falta que para mí es una FALTA en realidad porque / yo como paraguayo soy paraguayo pero encima el guaraní / yo no sé / tres o cuatro palabras o sea / también un jopara / que es una mezcla [...]

La promoción de la lengua de los antepasados precolombinos en el contexto hispanoamericano se percibe come signo distintivo "único":

[...] CA: ¿pero entonces el guaraní es importante / para vosotros / entre las características del Paraguay el guaraní cuenta?

$\mathrm{F}_{4}$ : es lengua oficial

GI: es importante

[...] creo que nosotros o sea / que / como grupo social de dónde venimos nunca nos fue muy introducido el guaraní como lengua / pero sí siempre fue/ tiene como una doble significación / es / la parte que nos une a los indios y que / que casi todos tienen vergüenza y que por eso es "vos sos indio / hablás guaranî" / pero también es como una de las pocas cosas / que nos diferencia / es algo único o sea / un tesoro XXX porque nadie habla guaraní / nosotros estamos solos

FI : claro / existen muy pocos países donde tienen algún registro de de de sus antepasados tan vivido como es acá el guaraní / que se mantiene [...]

Aunque quede la nación paraguaya fundamentalmente bi/(pluri)cultural y bilingüe:

\footnotetext{
${ }^{6}$ Los grupos de discusión de los que son extractos los discursos citados a continuación han sido organizados y grabados en Asunción del Paraguay por Carmen Alén Garabato (CA) y Henri Boyer.
} 
[...] CA: a ver / pero el Paraguay ¡es un país bilingüe? / ¿no?

F4: sí

CA: ¡eso es importante?

F4: sí / super / o sea la riqueza / o sea / tipo dos mundos / unidos /

CA: pero si no lo sois / ustedes no son bilingües //

Gi: pero nosotros somos //

FI: ¡somos desubicados!

G2: y es mentira eso que dice la gente que el que no habla guaraní no es paraguayo / nosotros estamos como dentro de una nación pero con dos culturas / a nosotros no más nos tocó eso / somos minoría / o sea a las personas que están en Asunción

\section{El examen parlamentario y el voto de la Ley de Lenguas del Paraguay}

En el momento del examen del proyecto de la Ley de Lenguas (esperado con impaciencia para concretar institucionalmente la cooficialidad del guaraní), las representaciones etnosociolingüisticas vigentes en Paraguay no dejaron de alimentar los discursos de los parlamentarios. Así, en el Senado de la República, los discursos epilingüísticos que acompańaron la discusión de la famosa ley, adoptada y luego promulgada por el presidente de la República a finales de 20 Io (Penner 20I6), han atestiguado, más allá de las divisiones partidistas, la importancia de un nacionalismo lingüístico (Boyer 2016) siempre dispuesto a expresarse. Algunos fragmentos de estos discursos, donde el énfasis compite con la hipérbole y donde el uso del guaraní se alterna con el castellano, son suficientes para apreciar la importancia de esta omnipresencia y el estatuto identitario (consensual) del guaraní ${ }^{7}$.

Por supuesto, se expresaron algunas reservas sobre la pertinencia de una ley de lenguas cuyo objetivo era que el guaraní fuera una lengua de uso pleno, con el argumento, en particular, de que se trataba de un proyecto que resultaría imposible llevar a cabo y que sería coercitivo. Así, el senador A. L. Jaeggli, tras algunas frases de autolegitimación y sacrificado al consenso nacionalista ("creo que el guaraní es parte de la idiosincrasia y de la nacionalidad, una nación, el Paraguay es una nación...”), afirma:

\footnotetext{
${ }^{7}$ Estos fragmentos han sido tomados del Diario de sesiones de la Honorable Cámara de Senadores del Paraguay (año 2010), concretamente de la sesión n. ${ }^{\circ}$ i 6 del 23 de septiembre y de la n. ${ }^{\circ}$ i 8 del 7 de octubre, disponibles en http://silpy.congreso.gov.py/descarga/sesion-I I 609 y http://silpy.congreso.gov.py/descarga/sesion-I I649, respectivamente (fecha de consulta: 27-III-20I9). Para un análisis en profundidad, $c f$. Penner 2016.
} 
Este es un proyecto de cumplimiento imposible. Esto es un proyecto de Ley en donde todos queremos que el guaraní siga siendo parte de nosotros, como va a seguir y le queremos obligar a la gente y queremos crear una institución pesada de nuevo para el Presupuesto y le queremos obligar a la gente que tenga sus carteles en la calle en guaraní y en castellano. [...] los sentimientos no se pueden obligar [...] yo quiero hablar guaraní porque me gusta hablar guaraní, porque me siento en una nación, pero que no me obliguen a hablar guaraní, porque voy a lograr absolutamente lo contrario. (Sesión n. ${ }^{\circ}$ i I 6 de 23 de septiembre de 2010)

Es decir, para terminar: "este proyecto es malísimo, es increíblemente malo".

Obviamente, el senador Jaeggli expresa aquí una posición minoritaria en nombre de la "libertad individual" y el supuesto "cumplimiento imposible" de la ley, que no tendrá repercusiones.

Lo que ha prevalecido en gran medida es la expresión de un "fetichismo de la lengua" (Bourdieu y Bolstanki i 975), capaz de neutralizar cualquier disensión. Y más allá del nacionalismo paraguayo, se trata ni más ni menos que de hacer del guaraní "el estandarte de la lucha de América por la recuperación de su identidad" (S. Ovelar, sesión n. ${ }^{\circ}$ i 6 de 23 de sept. de 2010). De manera general, el guaraní se celebra a través de calificativos (siempre de naturaleza identitaria) pero con varias facetas, perfectamente complementarias:

El guaraní es una maravilla. (J. C. Galaverna, sesión n. i I 6 de 23 de sept. de 20Io)

[Una] lengua materna que al fin es nuestra lengua originaria. (I. R. González, sesión n. ${ }^{\mathrm{o}}$ I I 8 de 7 de oct. de 20Io)

El guaraní es incontestablemente portador de una identidad dual, originalidad del nacionalismo lingüístico paraguayo (el guaraní es el idioma de los orígenes pero también el marcador indeleble de una nación mestiza, nacida de la fusión carnal del conquistador y de la india). Así lo indica el senador J. M. Bóbeda:

[el guaraní] es innato de la raza, nuestra raza guaraní mezclada con la europea, algunos sin mezclarse, teniendo la ciudadanía paraguaya, es innato, es concomitante con el ser nacional el lenguaje, el idioma guaraní. (Sesión n. ${ }^{o}$ i I 8 de 7 de oct. de 20 Io)

El texto de la Ley de Lenguas, definitivamente votado y promulgado en $20 \mathrm{Io}^{8}$, da un marco jurídico y administrativo muy ambicioso a la gestión glotopolítica del Paraguay. Deja constancia de la existencia de varias identidades en el Paraguay contemporáneo, instalando al mismo tiempo una jerarquía y abarcando los medios (disposiciones y dispositivos) para respetar esa pluralidad y su jerarquización, en conformidad con la definición constitucional del país como Estado "pluricultural y bilingüe” (art. 2). Así, se crea una estructura organizativa específica, “órgano dependiente

\footnotetext{
${ }^{8}$ Boyer y Penner (2012) proponen las versiones castellana y en guaraní de esta ley.
} 
de la Presidencia de la República” (art. 3 I), para la implementación de la política lingüística y la aplicación de la Ley de Lenguas: la Secretaría de Políticas Lingüisticas (el plural tiene su importancia) y en su seno la Dirección General de Planificación Lingüistica, encargada especialmente de la "normalización de todas las lenguas utilizadas en el Paraguay, en especial de las lenguas oficiales, en todos los ámbitos de la interacción social" (art. 37; la cursiva es mía) ${ }^{9}$. Se constituye, asimismo, una Academia de la Lengua Guaraní encargada de la normativización del idioma guaraní "en sus aspectos ortográfico, lexicológico, terminológico, gramatical y discursivo" $(\text { art. } 45)^{10}$. Se especifica efectivamente el marco de un "Estado pluricultural y bilingüe":

I. con una configuración lingüística compleja:

- dos lenguas oficiales (el guaraní y el castellano);

— varias lenguas y culturas "de los pueblos indígenas que habitan el territorio nacional” (sin más precisiones);

— las lenguas de las "comunidades culturales no indígenas" (sin más precisiones);

2. con una intrincación de identidades:

- la "identidad cultural de la nación", con sus dos lenguas oficiales:

a) el guaraní, "signo de la identidad cultural de la nación, instrumento de cohesión nacional y medio de comunicación de la mayoría de la población paraguaya" (art. 3);

b) el castellano;

- la(s) identidad(es) étnica(s) con las "lenguas y culturas" de los "pueblos indígenas" (art. I2).

\section{Conclusión}

En resumen, se asume la deuda etnosociolingüística, se respeta la realidad demolingüística: estos son los rasgos destacados del espíritu de esta Ley de Lenguas, que, al aplicarse conforme a este espíritu, tiene que movilizar muchas energías... y muchos recursos. Un verdadero reto para un pequeño país en situación difícil. Por eso hay que celebrar el valor de este gesto institucional y su importancia para los investigadores, los sociolingüistas en primer lugar: podría demostrar, si su implementa-

\footnotetext{
${ }^{9}$ En el seno de la Secretaría de Politicas Lingüisticas, se crean, además, una Dirección General de Documentación y Promoción de las Lenguas Indigenas y una Dirección General de Investigación Lingüistica.

${ }^{10}$ Tarea importantísima si se quiere avanzar de manera significativa hacia una auténtica normalización de los usos del guaraní.
} 
ción glotopolítica está a la altura del reto, que la identidad (lingüístico-cultural) "nacional" puede ser concebida colectivamente de manera perfectamente democrática y no discriminatoria ${ }^{11}$.

Pero, como enfatiza acertadamente Niro (20 I 2), la ley dejaba el proceso de normativización (requisito necesario, si no indispensable, para una normalización efectiva) ampliamente abierto, lo que suponía superar las disensiones entre los actores sociolingüísticos involucrados: varios de los artículos de la ley (I 4, I 5, I 6, I 8 y 23) indicaban que las directivas anunciadas entrarían en vigor "una vez establecidos el alfabeto y la gramática oficial del idioma guaraní".

La mirada sobre la situación glotopolítica post Ley de Lenguas que propone Hedy Penner (20I6), en particular por lo que toca a la actividad de la Academia de la Lengua Guaraní ${ }^{12}$, es más bien escéptica. Y es cierto que, como escribe la colega paraguaya,

Probablemente el punto de mayor importancia concierne al modelo de lengua. Este no podrá ser un modelo decretado desde arriba y elaborado tras puertas cerradas, ni ser concebido como una lengua indígena aun en boca de hablantes de antes de la colonización espańola, marcada de una hipotética pureza. (Penner 2016: 303)

Y sobre esta cuestión, en el seno de la Academia "las posturas no solo son radicales y antagónicas, sino también excluyentes" (ib.: 300), lo que frena forzosamente la normativización y, en consecuencia, la normalización del guaraní.

Pero, a pesar de obstáculos bien reales, parece que la normativización está avanzando: después del alfabeto (aprobado en diciembre de 2015 ), la Academia acaba de publicar (agosto de 2018) la Gramática oficial de la lengua guaraní, lo que supone que en 202 I la cooficialidad debería concretarse definitivamente.

Se sabe que no faltarán dificultades para llegar a la plena normalización del guaraní paraguayo, pero merece la pena seguir observando el desarrollo de esta normalización ejemplar, sobre todo si se toma en cuenta el contexto socioeconómico en el que se desarrolla este proceso glotopolítico: el de un país pobre, pero leal con su "lengua madre"...

${ }^{11} \mathrm{Mi}$ conocimiento y comprensión de las propuestas que han desembocado en la redacción del anteproyecto de la Ley de Lenguas y sus implícitos han sido ampliamente facilitados por varios encuentros en Asunción con la Comisión Nacional de Bilingüismo y por mi participación organizativa en las Jornadas Franco-Paraguayas de Sociolingüística, que tuvieron lugar en la Embajada de Francia en Paraguay bajo la coordinación de Caroline Natali (Service de Coopération et d'Action Culturelle) del 6 al io de agosto de 2007, con el tema Desafios sociolingüisticos del Paraguay actual.

${ }^{12}$ Los artículos 43, 44, 45 y 46 (Título II, Capítulo II) de la Ley de Lenguas van dedicados a la Academia de la Lengua Guaraní. 


\section{REFERENCIAS BIBLIOGRÁFICAS}

AMSELlE, Jean-Loup (200I): Branchements, Paris: Flammarion.

Bourdieu, Pierre y Luc BOLTANSKI (I975): "Le fétichisme de la langue”, Actes de la Recherche en Sciences Sociales, I(4), pp. 2-32. https://doi.org/I0.3406/arss.1975.34I7.

BOYER, Henri (2008): Langue et identité. Sur le nationalisme linguistique, Limoges: Lambert Lucas.

BOYER, Henri (2007): "Le stéréotypage ambivalent comme indicateur de conflit diglossique", en Henri Boyer (ed.), Stéréotypage, stéréotypes: fonctionnements ordinaires et mises en scène, Paris: L'Harmattan, t. 4, pp. 39-47.

BOYER, Henri (2016): “Identité (nationale), nationalisme linguistique et politique linguistique. Réflexions à partir de quelques situations contemporaines", Les Cahiers du GEPE, 8. http://cahiersdugepe. misha.fr/index.php?id=2948 (27-III-2019).

Boyer, Henri y Hedy PenNer (dirs.) (2012): Le Paraguay bilingue / El Paraguay bilingüe, Paris: L'Harmattan.

CORVAlan, Graziella (198 I [1977]): Paraguay: nación bilingüe, Asunción: Centro Paraguayo de Estudios Sociológicos.

Corvalan, Graziella (2006): Las políticas lingüísticas del Paraguay: rol del Estado, Asunción: Consejo Nacional de Educación y Cultura.

FISHMAN, Joshua A. (200I): Llengua $i$ identitat, Alzira: Bromera.

GYNAN, Shaw Nicholas (2003): El bilingüismo paraguayo: aspectos sociolingüisticos, Asunción: Universidad Evangélica del Paraguay.

LAFONT, Robert (1986): "Contrôle d'identités", en Robert Lafont (ed.), La production d'identités, Montpellier: Université Paul-Valéry / CNRS, pp. 5-18.

MELIA, Bartomeu (I997 [1988]): “El guaraní dominante y dominado”, en Bartomeu Melià, Una nación, dos culturas, Asunción: Centro de Estudios Paraguayos "Antonio Guasch" (CEPAG), pp. 39-5 I.

Niro, Mateo (2012): "Sobre consensos y disensos en la Ley de lenguas de Paraguay", en Henri Boyer y Hedy Penner (dirs.), Le Paraguay bilingue / El Paraguay bilingüe, Paris: L'Harmattan, pp. I35-2 I 9.

PENNER, Hedy (20 Io): “Jopara: la face méprisée du guarani ou/et du bilinguisme?", en Henri Boyer (dir.), Hybrides linguistiques. Genèses, statuts, fonctionnements, Paris: L'Harmattan, pp. I75-20 I.

PENNER, Hedy (2016): “La Ley de lenguas en el Paraguay: ¿un nuevo ímpetu coercitivo?”, en Carmen Alén Garabato, Ksenija Djordjevic Léonard, Patricia Gardies, Alexia Kis-Marck, Guy Lochard (eds.), Rencontres en sciences du langage et de la communication, Paris: L'Harmattan, pp. 279-307.

ZAJICOVA, Lenka (2009): El bilingüismo paraguayo, Madrid / Frankfurt am Main: Iberoamericana/Vervuert.

ZuCCOlillo F., Gabriela (2000): Lengua y nación: el rol de las élites morales en la oficialización del guarani (Paraguay 1992) [tesis doctoral], Buenos Aires: Universidad de Buenos Aires. 